\title{
Factors Associated with the Success Rate of Endoscopic Retrograde Cholangiopancreatography with Standard Technique followed by Laparoscopic Cholecystectomy in the Management of Choledocholithiasis: A Single-Center Experience
}

\author{
Chayanon Konsue ${ }^{1}$ Chalerm Eurboonyanun ${ }^{1 \oplus}$ Somchai Ruangwannasak ${ }^{1}$ Kulyada Eurboonyanun ${ }^{2}$

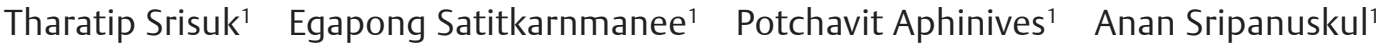

\author{
${ }^{1}$ Department of Surgery, Faculty of Medicine, Khon Kaen University, \\ Khon Kaen, Thailand \\ ${ }^{2}$ Department of Radiology, Faculty of Medicine, Khon Kaen \\ University, Khon Kaen, Thailand
}

\begin{abstract}
Address for correspondence Chalerm Eurboonyanun, MD, Department of Surgery, Faculty of Medicine, Khon Kaen University, 123 Mittrapharp Highway, Mueang, Khon Kaen 40002, Thailand (e-mail: chaleu@kku.ac.th).
\end{abstract}

\author{
Abstract \\ Keywords \\ - CBD stones \\ - ERCP \\ - choledocholithiasis \\ - standard technique \\ - difficult stones \\ - endoscopic retrograde \\ cholangiopancreatog- \\ raphy \\ - laparoscopic \\ cholecystectomy \\ - conversion
}

Background Choledocholithiasis is the most common benign biliary disease. Endoscopic retrograde cholangiopancreatography (ERCP) followed by laparoscopic cholecystectomy (LC) has been the first-line therapy in recent years, although laparoscopic common bile duct exploration has promising results. This retrospective study aimed to define the factors associated with biliary clearance by standard ERCP technique and conversion rate of LC.

Materials and Methods We retrospectively evaluated the records of 217 choledocholithiasis patients who had undergone ERCP with stone removal by the standard technique from 2010 to 2018. A failed ERCP was defined when the first ERCP session could not remove the stones. The number of patients who later underwent open cholecystectomy or LC was also recorded. Conversion was defined when LC had to be converted OC.

Statistical Analysis Student's t-test was used for the comparison of continuous variables. Nominal variables were analyzed using Pearson's chi-square test or Fisher's exact test. Binary logistic regression was performed for multivariate analysis.

Results The rate of successful biliary clearance was $81.1 \%$. Of the patients, 109 (50.2\%) had difficult stones. Increasing age $(p=0.004)$, increasing number $(p=0.001)$, and increasing size of stone $(p<0.001)$ were the three significant factors that were associated with the failure of biliary clearance. The difficult stone group had a higher failure rate of ERCP and a higher conversion rate of LC compared with the easy stone group ( $p=0.001$ and $p=0.027$, respectively).

Conclusions ERCP with the standard technique is a highly effective and safe management option for patients with common bile duct (CBD) stones. The difficult stone group was found to be an independent risk factor that affected the success rate of both ERCP and the following LC. Difficult stone criteria should be assessed to identify a patient who might benefit from laparoscopic CBD exploration. 


\section{Introduction}

Choledocholithiasis, the presence of stones in the common bile duct (CBD), is the most common benign biliary disease, and is found in $10 \%$ to $15 \%$ of the population. The condition occurs more frequently in patients with advanced ages. ${ }^{1}$ The majority of choledocholithiasis come from the migration of stone from the gallbladder into the CBD. However, 10 to 18\% of patients who have previously undergone cholecystectomy also can present with CBD stones after surgery. ${ }^{2}$ For a patient with choledocholithiasis, early treatment is needed to reduce the risk of fatal complications such as severe pancreatitis and severe cholangitis. ${ }^{3}$

There are many options to treat choledocholithiasis, such as CBD exploration either by open- or minimally-invasive approaches or endoscopy intervention. However, the development of stone extraction techniques in recent years has enabled endoscopic retrograde cholangiopancreatography (ERCP) to be the first-line therapy. Stone extraction with ERCP has high success rates and low complication rates. However, failure of treatment occasionally occurs in the following setting: (1) stone diameter is greater than $1.5 \mathrm{~cm}$, (2) there are more than three stones, (3) there is impaction of the stone(s), (4) a periampullary diverticula is present, or (5) there is a narrowing of the bile duct distal to the stone.

Sphincterotomy and stone removal by balloon or dormia basket, with or without a mechanical lithotripter, is considered to be the standard technique. When the standard approach fails, additional interventional techniques such as electrohydraulic/laser lithotripsy or extracorporeal shockwave lithotripsy can be used. However, those options are only available in limited centers. ${ }^{4,5}$

Biliary decompression with plastic endobiliary stent would be an alternative approach if another advanced option were unavailable. However, this method requires one or more repeated ERCP sessions to achieve success. ${ }^{6}$ Better understanding of the factors associated with successful complete biliary clearance would help endoscopists to predict the chance of success and to prepare the additional instruments before starting the procedure.

The primary aim of this study was to investigate the factors that are associated with the success rate of biliary clearance of ERCP with standard technique followed by laparoscopic cholecystectomy (LC) in patients with CBD stone. The secondary aim was to identify the characteristic of patients with difficult stones.

\section{Materials and Methods}

\section{Ethics}

The project was approved by the Khon Kaen University Ethics Committee for Human Research (registration number: HE601264).

\section{Study Population}

From 2010 to 2018, there were 217 patients with CBD stones who underwent therapeutic ERCP at the Surgical Endoscopy
Unit, Srinagarind Hospital, Khon Kaen University. Patients age younger than 18 years or older than 80 years were excluded. The diagnosis of choledocholithiasis was established in the presence of clinical symptoms and the detection of bile duct stone(s) on computed tomography (CT) or magnetic resonance cholangiopancreatography (MRCP).

\section{Procedure}

All procedures were performed by seven endoscopists using a standard endoscope (Olympus TGF-145 or FujiFilm ED-580XT); five endoscopists had more than 5 years of experience, whereas two endoscopists had less than 5 years of experience. The written informed consent was obtained from every patient before the procedure. The patients were anesthetized under conscious sedation technique with midazolam or propofol without orotracheal intubation. For duodenal relaxation, butylscopolamine was administered. In case the patient's condition was not appropriate, standard general anesthesia would, instead, be used.

We used $10 \%$ lidocaine spray for pharyngeal anesthesia. Intravenous antibiotics were given before the start of the procedure. Patients were in the prone position during the procedure. Endoscopic sphincterotomy was performed after deep cannulation of the bile duct with a papillotome. In case of any stricture of bile duct distal to the stone, balloon dilatation with a 6- or 8-mm balloon was performed. If transpapillary dilatation was needed, sphincteroplasty with a 10-, 12-, or $15-\mathrm{mm}$ balloon was performed. Standard techniques were implemented for the removal of stones, with a balloon catheter, a four-wire basket catheter, or both as a tool. Mechanical lithotripsy or endobiliary stent placement was executed in a difficult case. If complete stone removal was not possible in the first session, the patient would be scheduled for surgery or sequential ERCP procedures within 2 to 3 months. To prevent post-ERCP pancreatitis, we used prophylactic pancreatic duct stent and/or indomethacin suppositories in the patient who had difficult biliary cannulation.

\section{Data Collection}

The following data were collected from the electronic medical records: age, sex, clinical presentation, physical examination, clinical diagnosis, blood tests, imaging- and endoscopic findings, endoscopic technique used, and short-term outcomes.

Difficult stone was defined by the presence of any of the following: stone diameter larger than $1.5 \mathrm{~cm}$, more than three stones, presence of periampullary diverticula, and narrowing of the biliary duct distal to the stone.

Post-ERCP complications were assessed and recorded using the definition from the 1991 consensus guidelines. ${ }^{7}$ Post-ERCP pancreatitis was defined as the new onset of abdominal pain with an elevation of serum amylase more than three times and persistent for more than 24 hours after the procedure. Hemorrhage was defined as clinical evidence of bleeding with a decrease of hematocrit of more than $6 \%$. Cholangitis was defined as an elevation in body temperature more than $38 \mathrm{C}$, presumably from the biliary cause. 
Perforation was diagnosed based on the detection of air or bile leakage by the cross-sectional imaging modality.

The number of patients who later underwent open cholecystectomy (OC) or LC was also recorded. A conversion was defined as an incidence when LC had to be converted to OC.

\section{Statistical Analysis}

Statistical analysis was performed using STATA software version 10 (StataCorp., College Station, Texas, United States). Continuous variables were expressed as means and standard deviation. Continuous variables were compared using Student's $t$-test. Categorical variables were expressed as number and percentage and were analyzed using Pearson's chi-square test or Fisher's exact test. Factors with p-values under 0.25 were included in the multivariate analysis using binary logistic regression. Results with p-values of less than 0.05 were considered to be statistically significant.

\section{Results}

We enrolled a total of 217 patients in this study. The overall mean age was $60.6 \pm 14$ years old, and 105 (48.4\%) of the patients were male. The majority $(62.7 \%)$ presented with cholangitis. The other presenting symptoms include abdominal pain, pancreatitis, and jaundice. The CBD stones were incidentally detected in eight patients. Regarding the number of stones, 118 (56.5\%) patients had single stones, whereas $91(43.5 \%)$ had multiple stones. The mean number and size of the stones were $1.47 \pm 1.03$ stones and $9.78 \pm 4.63 \mathrm{~mm}$, respectively. The mean size of the CBD was $11.52 \pm 5.13 \mathrm{~mm}$. Thirty-five (16.1\%) patients had undergone prior cholecystectomy. Of all the patients, 118 (54.4\%) had at least one comorbidity, with hypertension being the most common comorbidity. Duodenal diverticulum was the most commonly found variation (-Table $\mathbf{1}$ ).

By using the standard technique, the success rate of biliary clearance in the first ERCP session was $81.1 \%(n=176)$. The success rate of ampullary cannulation was $94.0 \%(n=204)$. Endoscopic sphincterotomy was performed in 142 (69.6\%) patients, and endoscopic sphincterotomy with additional endoscopic balloon dilatation was performed in 62 (30.4\%) patients. Additional mechanical lithotripsy was adopted in three $(1.5 \%)$ patients. The stones were removed by balloon extraction in $200(98.6 \%)$ patients. Plastic stent placement was inserted in 49 (22.6\%) patients who were suspected of having impacted stone, residual stone, large stone, bile duct stricture, bile duct tumor, and clinical sepsis.

When the patients were divided into two groups based on the success of biliary clearance, there was no significant difference in terms of gender, body mass index, clinical presentation, initial serum alkaline phosphatase, and total serum bilirubin. However, the differences were significant between the patients of the two groups in terms of the age, initial serum alanine aminotransferase (ALT), initial serum aspartate aminotransferase (AST), prior cholecystectomy, the existence of duodenal diverticulum, number of stones, size
Table 1 Demographic data of patients who underwent ERCP with the standard technique

\begin{tabular}{|l|l|}
\hline Variables & Results \\
\hline Age & $60.6 \pm 14$ \\
\hline Gender, male/female & $\begin{array}{l}105(48.4 \%) / 112 \\
(51.6 \%)\end{array}$ \\
\hline Clinical presentation & \\
\hline Cholangitis & $136(62.7 \%)$ \\
\hline Pancreatitis & $10(4.6 \%)$ \\
\hline Abdominal pain & $57(26.3 \%)$ \\
\hline Jaundice & $6(2.8 \%)$ \\
\hline Incidental findings & $8(3.7 \%)$ \\
\hline Single stone/multiple stones & $91(43.5 \%)$ \\
\hline Number of stone (stone) & $1.47 \pm 1.03$ \\
\hline Size of stone (mm) & $9.78 \pm 4.63$ \\
\hline Size of bile duct (mm) & $11.52 \pm 5.13$ \\
\hline History of cholecystectomy & $35(16.1 \%)$ \\
\hline Comorbidity & $118(54.4 \%)$ \\
\hline Hypertension & $73(33.6 \%)$ \\
\hline Diabetes mellitus & $48(22.1 \%)$ \\
\hline Heart disease & $13(6.0 \%)$ \\
\hline Liver disease & $9(4.1 \%)$ \\
\hline Chronic kidney disease & $8(3.7 \%)$ \\
\hline Pulmonary disease & $6(2.7 \%)$ \\
\hline Anatomical variation & $44(20.3 \%)$ \\
\hline Duodenal diverticula & $4(1.8 \%)$ \\
\hline Duodenal polyp & $13(6.0 \%)$ \\
\hline Bile duct stricture & $4(3.1 \%)$ \\
\hline Conversion from laparoscopic cholecys- & \\
\hline tectomy to open cholecystectomy & $90 p a n c a t$ \\
\hline
\end{tabular}

Abbreviation: ERCP, endoscopic retrograde cholangiopancreatography.

of stone, mean size of CBD, and the identification of difficult stones (-Table 2).

According to the multivariate analysis with binary logistic regression, the only three independent risk factors affecting the outcome of the ERCP were the patient's age, number of stones, and size of the stone ( - Table 3 ).

\section{Difficult Stones}

Of the 217 patients, 109 (50.2\%) had difficult stones. There were no significant differences between the difficult group and the easy stone group in terms of age, laboratory parameters, and clinical presentation. Nevertheless, the percentage of male patients with difficult stones was significantly higher than the percentage of their female counterparts $(p=0.025)$. The success rate of biliary clearance in the first ERCP session was significantly higher in the easy stone group $(p=0.001)$. The overall complication occurred more frequently in the difficult stone group. However, the difference was not statistically significant (-Table 4 ). 
Table 2 Main difference between patients with success and failure in first ERCP sessions

\begin{tabular}{|c|c|c|c|}
\hline Variables & Success $(n=176)$ & Unsuccessful $(n=41)$ & $p$-Value \\
\hline Age & $59.09 \pm 14.32$ & $67.32 \pm 12.96$ & $<0.001$ \\
\hline Gender, male/female & 85 (48.29\%) & $21(51.21 \%)$ & 0.736 \\
\hline BMI $\left(\mathrm{kg} / \mathrm{m}^{2}\right)$ & $23.27 \pm 3.90$ & $22.45 \pm 3.78$ & 0.226 \\
\hline \multicolumn{4}{|l|}{ Clinical presentation } \\
\hline Cholangitis & 109 (61.93\%) & 27 (65.85\%) & 0.640 \\
\hline Pancreatitis & 7 (3.98\%) & $3(7.32 \%)$ & 0.359 \\
\hline Abdominal pain & $50(28.41 \%)$ & $6(14.63 \%)$ & 0.070 \\
\hline Jaundice & $4(2.27 \%)$ & $2(4.88 \%)$ & 0.360 \\
\hline Incidental findings & $6(3.41 \%)$ & $2(4.88 \%)$ & 0.653 \\
\hline \multicolumn{4}{|l|}{ Laboratory findings } \\
\hline ALT & $79.92 \pm 92.24$ & $44.27 \pm 54.21$ & 0.018 \\
\hline AST & $80.80 \pm 84.40$ & $50.02 \pm 65.88$ & 0.030 \\
\hline ALP & $215.60 \pm 167.62$ & $183.98 \pm 202.96$ & 0.298 \\
\hline Total bilirubin & $3.02 \pm 5.36$ & $2.63 \pm 5.90$ & 0.681 \\
\hline Jaundice $(T B>2.5)$ & $50(28.41 \%)$ & $6(14.63 \%)$ & 0.069 \\
\hline \multicolumn{4}{|l|}{ Endoscopic findings } \\
\hline Normal & $114(64.77 \%)$ & $20(48.78 \%)$ & 0.05 \\
\hline Diverticulum & $29(16.48 \%)$ & $15(36.58 \%)$ & 0.004 \\
\hline Previous sphincterotomy & $11(6.25 \%)$ & $2(4.87 \%)$ & 0.739 \\
\hline Duodenal polyp & $4(2.27 \%)$ & $0(0 \%)$ & 0.331 \\
\hline CDD & $0(0 \%)$ & $1(2.44 \%)$ & 0.038 \\
\hline Bulging ampulla & $1(0.57 \%)$ & $0(0 \%)$ & 0.629 \\
\hline CBD stricture & $12(6.82 \%)$ & $1(2.43 \%)$ & 0.288 \\
\hline Others & $5(2.84 \%)$ & $2(4.89 \%)$ & \\
\hline Previous cholecystectomy & $22(14.28 \%)$ & $11(36.67 \%)$ & 0.021 \\
\hline Number of stones & $1.30 \pm 0.69$ & $2.40 \pm 1.83$ & $<0.001$ \\
\hline Single stone proportion & 107 (63.69\%) & $11(26.83 \%)$ & $<0.001$ \\
\hline Mean maximum size of stone (mm) & $8.78 \pm 3.93$ & $13.69 \pm 5.10$ & $<0.001$ \\
\hline Big stone $>15 \mathrm{~mm}$ & $43(24.43 \%)$ & $21(51.22 \%)$ & $<0.001$ \\
\hline Mean size of bile duct (mm) & $10.48 \pm 3.88$ & $15.63 \pm 7.12$ & $<0.001$ \\
\hline Difficult stone & $79(44.88 \%)$ & $30(73.17 \%)$ & 0.001 \\
\hline LOS (days) & $10.12 \pm 3.88$ & $5.08 \pm 11.53$ & $<0.001$ \\
\hline
\end{tabular}

Abbreviations: ALP, alkaline phosphatase; ALT, alanine transaminase; AST, aspartate transaminase; BMI, body mass index; CBD, common bile duct; CDD, choledochoduodenostomy; ERCP, endoscopic retrograde cholangiopancreatography; LOS, length of stay; TB, total bilirubin.

Table 3 Multivariate analysis for factors affecting endoscopic success

\begin{tabular}{|l|l|l|l|}
\hline Variables & Odds ratio & $95 \%$ confidence interval & $p$-Value \\
\hline Age & 0.920 & $0.869-0.974$ & 0.004 \\
\hline Abdominal pain & 3.483 & $0.735-16.509$ & 0.116 \\
\hline Number of stone & 0.408 & $0.235-0.709$ & 0.001 \\
\hline Size of stone & 0.820 & $0.736-0.913$ & $<0.001$ \\
\hline Diverticulum & 0.997 & $0.248-4.012$ & 0.997 \\
\hline
\end{tabular}

\section{Complications}

There were post-ERCP complications in 30 (13.8\%) patients. Pancreatitis was the most common complication followed by cholangitis. There were three (1.38\%) cases of post-ERCP mortality. The overall length of hospital stay was $6.0 \pm$ 6.4 days ( - Table 4 ). 
Table 4 Characteristic and outcome difference between patients in the easy and difficult stone groups

\begin{tabular}{|c|c|c|c|}
\hline Variables & Easy stone $(n=108)$ & Difficult stone $(n=109)$ & $p$-Value \\
\hline Age & $58.76 \pm 14.53$ & $62.50 \pm 14.11$ & 0.055 \\
\hline Gender (male/female), n (\%) & $61(56.48 \%) / 47$ (43.52\%) & $45(41.28 \%) / 64$ (58.72\%) & 0.025 \\
\hline $\mathrm{BMI}\left(\mathrm{kg} / \mathrm{m}^{2}\right)$ & $23.40 \pm 4.07$ & $22.84 \pm 3.69$ & 0.296 \\
\hline \multicolumn{4}{|l|}{ Lab } \\
\hline ALT & $74.19 \pm 85.49$ & $72.19 \pm 89.58$ & 0.866 \\
\hline AST & $71.48 \pm 74.49$ & $78.47 \pm 89.01$ & 0.531 \\
\hline ALP & $192.79 \pm 142.01$ & $226.30 \pm 201.36$ & 0.158 \\
\hline Total bilirubin & $3.26 \pm 6.35$ & $2.64 \pm 4.40$ & 0.408 \\
\hline Jaundice (TB > 2.5) & $30(27.78 \%) / 78$ (72.22\%) & $26(23.85 \%) / 83(76.15 \%)$ & 0.509 \\
\hline \multicolumn{4}{|l|}{ Presentation } \\
\hline Cholangitis & $67(62.03 \%)$ & 69 (63.30\%) & 0.847 \\
\hline Pancreatitis & 7 (6.48\%) & $3(2.75 \%)$ & 0.191 \\
\hline Abdominal pain & $31(28.70 \%)$ & $25(22.94 \%)$ & 0.333 \\
\hline Jaundice & $1(0.93 \%)$ & $5(4.59 \%)$ & 0.100 \\
\hline Incidental findings & $2(1.85 \%)$ & $6(5.50 \%)$ & 0.154 \\
\hline Success rate & 97 (89.81\%) & $79(72.47 \%)$ & 0.001 \\
\hline LOS (days) & $5.46 \pm 4.34$ & $6.60 \pm 7.88$ & 0.191 \\
\hline Complication & $12(11.11 \%)$ & $18(16.51 \%)$ & 0.249 \\
\hline Post-ERCP pancreatitis & $6(5.56 \%)$ & $8(7.34 \%)$ & 0.593 \\
\hline Cholangitis & $5(4.63 \%)$ & $5(4.59 \%)$ & 0.988 \\
\hline Perforation & $0(0.00 \%)$ & $1(0.92 \%)$ & 1.000 \\
\hline Hemorrhage & $1(0.92 \%)$ & $2(1.83 \%)$ & 1.000 \\
\hline Multiorgan failure & 1 (0.92\%) & $3(2.75 \%)$ & 0.622 \\
\hline 30-d mortality & $1(0.92 \%)$ & $2(1.83 \%)$ & 1.000 \\
\hline $\begin{array}{l}\text { Conversion from laparoscopic chole- } \\
\text { cystectomy to open cholecystectomy }\end{array}$ & $0.00 \%(N=77)$ & $7.41 \%(N=54)$ & 0.027 \\
\hline
\end{tabular}

Abbreviations: ALP, alkaline phosphatase; ALT, alanine transaminase; AST, aspartate transaminase; BMI, body mass index; ERCP, endoscopic retrograde cholangiopancreatography; LOS, length of stay; TB, total bilirubin.

\section{Following Cholecystectomy}

A total of 137 patients underwent cholecystectomy in our hospital, whereas the rest had previous cholecystectomy or refused additional cholecystectomy in our hospital. There were 131 patients who underwent LC, but 4 (3.1\%) of them had to be converted to OC due to severe adhesion or unstoppable bleeding. The conversion group had a significantly older age and proportion of difficult stones than the unconverted group ( $p=0.003$ and $p=0.027$, respectively) (- Table 5).

\section{Discussion}

Nowadays, ERCP and laparoscopic CBD exploration (LCBDE) have become the two most popular methods in the management of choledocholithiasis. In a previous meta-analysis, both procedures show promising results without significant differences in mortality, morbidity, retained stones, and failure rate. ${ }^{8}$ LCBDE is a single-stage management, whereas ERCP followed by LC is a two-stage management. Although LCBDE has better results in regard to the lower costs and shorter hospital stays, many are hesitant to perform the procedure due to insufficient training and a great incidence of biliary leakage. ${ }^{9,10}$ On the other hand, the improvement of endoscopic technique such as mechanical lithotripsy, laser lithotripsy, and cholangioscopy made ERCP the popular choice. ${ }^{11-16}$

ERCP with standard stone removal technique is the simplest procedure in endoscopy that most of the hospital can perform, whereas laser lithotripsy is available only in some tertiary centers especially in a low- or middle-income country. ${ }^{17-19}$ It would be beneficial to the treatment planning if the success or failure of ERCP with the standard stone removal can be predicted, and a patient with a higher risk of OC conversion can be identified.

In our study, $81.1 \%$ of patients with CBD stones were successfully treated with the standard technique in the first ERCP session, which was lower than the common range $(87-100 \%)^{20,21}$ However, half of the patients in our population were in the difficult stone group, which was significantly higher than the $15 \%$ rate reported in previous literature.,5,22 The success rate of ampullary cannulation was $94 \%$, which was comparable with the previous literature. ${ }^{23}$ The success rate of clearance was $86.3 \%$, with successfully ampullary cannulation. 
Table 5 Following laparoscopic cholecystectomy after ERCP

\begin{tabular}{|l|l|l|l|}
\hline & Laparoscopic cholecystectomy $(N=127)$ & Converted to open cholecystectomy $(N=4)$ & $p$-Value \\
\hline Age & $57.31 \pm 14.51$ & $76.25 \pm 1.50$ & 0.003 \\
\hline Gender, male/female & $58(45.67 \%) / 69(54.33 \%)$ & $4(100.00 \%) / 0(0.00 \%)$ & 0.048 \\
\hline Body mass index $\left(\mathrm{kg} / \mathrm{m}^{2}\right)$ & $23.28 \pm 4.10$ & $21.54 \pm 3.23$ & 0.396 \\
\hline Clinical presentation & & $3(75.00 \%)$ & 0.632 \\
\hline Cholangitis & $71(55.90 \%)$ & $1(25.00 \%)$ & 0.173 \\
\hline Pancreatitis & $5(3.94 \%)$ & $0(0.00 \%)$ & 0.300 \\
\hline Abdominal pain & $44(34.65 \%)$ & $0(0.00 \%)$ & 1.000 \\
\hline Jaundice & $3(2.36 \%)$ & $0(0.00 \%)$ & 1.000 \\
\hline Incidental finding & $4(3.15 \%)$ & $0(0.00 \%)$ & 1.000 \\
\hline Overall complication & $14(11.02 \%)$ & $0(0.00 \%)$ & 1.000 \\
\hline Pancreatitis & $11(8.66 \%)$ & $0(0.00 \%)$ & 1.000 \\
\hline Cholangitis & $3(2.36 \%)$ & $4(100.00 \%)$ & 0.027 \\
\hline Difficult stone & $50(39.37 \%)$ & & \\
\hline Ab & & \\
\hline
\end{tabular}

Abbreviation: ERCP, endoscopic retrograde cholangiopancreatography.

We analyzed the data to find the factors contributing to the success rate of biliary clearance. Univariate analysis found a significant relationship between the treatment outcome and the following factors: the patient's age, initial serum ALT, initial serum AST, duodenal diverticulum, and number and size of stones. However, only three independent factors, namely age, number of stones, and size of stones, were significantly related to the outcomes of biliary clearance in multivariate analysis. Younger patients in our study had a higher rate of success than older patients, which was similar to the previous study. ${ }^{4}$ The results of increasing number and size of stones were also significantly correlated with a lower rate of success similar to the previous literature. ${ }^{4,5}$

There is no consensus regarding definition of difficult stone. In the American Society for Gastrointestinal Endoscopy guideline, clinical situations associated with difficult bile duct stone extraction were (1) stone larger than $15 \mathrm{~mm}$, (2) stone that cannot be captured in the basket or mechanical lithotripsy, (3) stone with complex biliary stricture, (4) stone in patients with altered upper gut anatomy, and (5) Mirizzi's syndrome. ${ }^{15}$ However, Ödemiş et al defined difficult stones as the stones that cannot be extracted in the first ERCP procedure using the standard technique; this was similar to the term for the successful procedure, not for a difficult stone, in our study. ${ }^{4}$

We divided patients into an easy group and a difficult stone group according to the criteria proposed in a previous study. ${ }^{5,22}$ We, however, decided to exclude the impaction of stone from the criteria because we could not predict that before starting the procedure. The proportion of female patients in the difficult-stone group was significantly higher than their male counterparts. The success rate of biliary clearance was significantly lower in patients with difficult stones. Thus, by identifying a patient with difficult stone, the endoscopist can prepare the team for the potential advance procedure and provide appropriate tools such as mechanical lithotripsy, laser lithotripsy, or extracorporeal shockwave lithotripsy before the start of ERCP to increase the chance of complete biliary clearance rate, similar to that reported in previous literature. ${ }^{24-28}$

We found a higher rate of complication in post-ERCP pancreatitis and cholangitis compared with $3.5 \%$ and $1.4 \%$, respectively, in the previous literature. ${ }^{29}$ We also found a similar rate of post-ERCP bleeding and ERCP-related perforation compared with previous literature. ${ }^{29}$ Our three patients who had post-ERCP mortality were all caused by severe cholangitis leading to multiorgan failure. The information on the risk factors of pancreatitis and cholangitis, such as sphincter of Oddi dysfunction, pancreatic intervention, and inadequate cleansing of the lumen during duodenoscopy, which were described in the previous studies, ${ }^{29,30}$ could not be accessed in our retrospective study.

The overall complication rate was $13.8 \%$, which was higher than that reported in the previous literature. To be specific, the rates of post-ERCP pancreatitis and post-ERCP cholangitis were higher, ${ }^{29}$ whereas the rates of ERCP-related hemorrhage and perforation were comparable with previous studies. Our mortality rate (1.4\%) was also higher than that previously reported. All three patients who were admitted to the hospital due to cholangitis were dead from multiorgan failure despite emergency ERCP with biliary drainage being performed. This difference in both the complication rate and the mortality rate between this study and the previous literature might be explained by a larger proportion of difficult stones in our study and the mixture of elective and emergency cases in our study population. ${ }^{29,30}$

Two-stage preoperative ERCP with stone removal followed by LC was the treatment of choice in our hospital. Our conversion rate was lower than that in the previous literature. ${ }^{31}$ Male gender, older age ( $>50$ years), obese patients (body mass index $>30 \mathrm{~kg} / \mathrm{m}^{2}$ ), and case performed by low-volume surgeons had a higher likelihood to conversion in overall LC, ${ }^{31-33}$ However, there was no single factor related to preoperative ERCP that would make LC more difficult except the number 
of ERCPs. ${ }^{34,35}$ In our study, we found a higher age of patient and a larger proportion of difficult stone in the conversion group with statistical significance.

\section{Limitation}

The main limitation of our study was its retrospective nature and a small incidence of the conversion. A larger prospective study would be indispensable to further assess the relationship between the risk factors and the outcomes of biliary clearance by the ERCP followed by LC.

\section{Conclusion}

ERCP with the standard technique followed by LC is a highly effective and safe procedure in the management of $\mathrm{CBD}$ stones. Difficult stone group was found to be an independent risk factor affecting the success rate of ERCP with standard technique followed by LC. Before the start of the ERCP procedure, difficult stone criteria should be applied to evaluate the difficulty and identify a patient who might benefit from ERCP followed by LC or LCBDE, boosting the success rate of biliary clearance.

\section{Conflict of Interest}

The authors declare that there is no conflict of interest regarding the publication of this paper.

\section{Acknowledgment}

We would like to express our special thanks to Research Affairs, Faculty of Medicine, Khon Kaen University, for financial support and statistical assistance.

\section{Reference}

1 Prachayakul V, Aswakul P, Bhunthumkomol P, Deesomsak M. Diagnostic yield of endoscopic ultrasonography in patients with intermediate or high likelihood of choledocholithiasis: a retrospective study from one university-based endoscopy center. BMC Gastroenterol 2014;14-165

2 Frossard JL, Morel PM. Detection and management of bile duct stones. Gastrointest Endosc 2010;72(4):808-816

3 Lynn AP, Chong G, Thomson A. Endoscopic retrograde cholangiopancreatography in the treatment of intraoperatively demonstrated choledocholithiasis. Ann R Coll Surg Engl 2014;96(1):45-48

4 Ödemiş B, Kuzu UB, Öztaş E, et al. Endoscopic management of the difficult bile duct stones: a single tertiary center experience. Gastroenterol Res Pract 2016;2016:8749583

5 McHenry L, Lehman G. Difficult bile duct stones. Curr Treat Options Gastroenterol 2006;9(2):123-132

6 Chan AC, Ng EK, Chung SC, et al. Common bile duct stones become smaller after endoscopic biliary stenting. Endoscopy 1998;30(4):356-359

7 Cotton PB, Lehman G, Vennes J, et al. Endoscopic sphincterotomy complications and their management: an attempt at consensus. Gastrointest Endosc 1991;37(3):383-393

8 Dasari BVM, Tan CJ, Gurusamy KS, et al. Surgical versus endoscopic treatment of bile duct stones. Cochrane Database Syst Rev 2013;(9):CD003327

9 Guan G, Sun C, Ren Y, Zhao Z, Ning S. Comparing a single-staged laparoscopic cholecystectomy with common bile duct exploration versus a two-staged endoscopic sphincterotomy followed by laparoscopic cholecystectomy. Surgery 2018; 164(5):1030-1034

10 Poulose BK, Arbogast PG, Holzman MD. National analysis of in-hospital resource utilization in choledocholithiasis management using propensity scores. Surg Endosc 2006;20(2):186-190

11 Tao T, Zhang M, Zhang QJ, et al. Outcome of a session of extracorporeal shock wave lithotripsy before endoscopic retrograde cholangiopancreatography for problematic and large common bile duct stones. World J Gastroenterol 2017;23(27): 4950-4957

12 Phalanusitthepha C, Augkurawaranon C, Sriprayoon T, Hokierti C, Akaraviputh T. Outcomes of endoscopic sphincteroplasty using large balloon dilatation for difficult common bile duct stone removal: a single endoscopist experience. J Med Assoc Thai 2014;97(7):699-704

13 Sauer BG, Cerefice M, Swartz DC, et al. Safety and efficacy of laser lithotripsy for complicated biliary stones using direct choledochoscopy. Dig Dis Sci 2013;58(1):253-256

14 Millat B, Fingerhut A, Deleuze A, et al. Prospective evaluation in 121 consecutive unselected patients undergoing laparoscopic treatment of choledocholithiasis. $\mathrm{Br} \mathrm{J}$ Surg 1995;82(9):1266-1269

15 Buxbaum JL, Abbas Fehmi SM, Sultan S, et al; ASGE Standards of Practice Committee. ASGE guideline on the role of endoscopy in the evaluation and management of choledocholithiasis. Gastrointest Endosc 2019;89(6):1075-1105.e15

16 Stefanidis G, Viazis N, Pleskow D, et al. Large balloon dilation vs. mechanical lithotripsy for the management of large bile duct stones: a prospective randomized study. Am J Gastroenterol 2011;106(2):278-285

17 Angsuwatcharakon P, Kulpatcharapong S, Ridtitid W, et al. Digital cholangioscopy-guided laser versus mechanical lithotripsy for large bile duct stone removal after failed papillary large-balloon dilation: a randomized study. Endoscopy 2019;51(11):1066-1073

18 Ang TL, Kwek ABE. Safety and efficacy of SpyGlass cholangiopancreatoscopy in routine clinical practice in a regional Singapore hospital. Singapore Med J 2019;60(10):538-544

19 DI Mitri R, Pellicano R, Eusebi LH, et al. Single versus two-operator endoscopic biliary cannulation technique: a multicenter matched-case analysis. Minerva Chir 2017;72(4):302-310

20 Elfant AB, Bourke MJ, Alhalel R, Kortan PP, Haber GB. A prospective study of the safety of endoscopic therapy for choledocholithiasis in an outpatient population. Am J Gastroenterol 1996;91(8):1499-1502

21 Maple JT, Ikenberry SO, Anderson MA, et al; ASGE Standards of Practice Committee. The role of endoscopy in the management of choledocholithiasis. Gastrointest Endosc 2011;74(4):731-744

22 Hochberger J, Bayer J, May A, et al. Laser lithotripsy of difficult bile duct stones: results in 60 patients using a rhodamine $6 \mathrm{G}$ dye laser with optical stone tissue detection system. Gut 1998;43(6):823-829

23 Williams EJ, Taylor S, Fairclough P, et al; BSG Audit of ERCP. Are we meeting the standards set for endoscopy? Results of a large-scale prospective survey of endoscopic retrograde cholangio-pancreatograph practice. Gut 2007;56(6):821-829

24 Hintze RE, Adler A, Veltzke W. Outcome of mechanical lithotripsy of bile duct stones in an unselected series of 704 patients. Hepatogastroenterology 1996;43(9):473-476

25 Rosa B, Moutinho Ribeiro P, Rebelo A, Pinto Correia A, Cotter J. Endoscopic papillary balloon dilation after sphincterotomy for difficult choledocholithiasis: a case-controlled study. World J Gastrointest Endosc 2013;5(5):211-218

26 Minami A, Hirose S, Nomoto T, Hayakawa S. Small sphincterotomy combined with papillary dilation with large balloon 
permits retrieval of large stones without mechanical lithotripsy. World J Gastroenterol 2007;13(15):2179-2182

27 Lee TY, Cheon YK, Choe WH, Shim CS. Direct cholangioscopy-based holmium laser lithotripsy of difficult bile duct stones by using an ultrathin upper endoscope without a separate biliary irrigating catheter. Photomed Laser Surg 2012; 30(1):31-36

28 Maydeo A, Kwek BEA, Bhandari S, Bapat M, Dhir V. Singleoperator cholangioscopy-guided laser lithotripsy in patients with difficult biliary and pancreatic ductal stones (with videos) Gastrointest Endosc 2011;74(6):1308-1314

29 Talukdar R. Complications of ERCP. Best Pract Res Clin Gastroenterol 2016;30(5):793-805

30 Pungpapong S, Kongkam P, Rerknimitr R, Kullavanijaya P. Experience on endoscopic retrograde cholangiopancreatography at tertiary referral center in Thailand: risks and complications. J Med Assoc Thai 2005;88(2):238-246
31 Sakpal SV, Bindra SS, Chamberlain RS. Laparoscopic cholecystectomy conversion rates two decades later. JSLS 2010;14(4):476-483

32 Rosen M, Brody F, Ponsky J. Predictive factors for conversion of laparoscopic cholecystectomy. Am J Surg 2002;184(3):254-258

33 Beliaev AM, Booth M. Late two-stage laparoscopic cholecystectomy is associated with an increased risk of major bile duct injury. ANZ J Surg 2016;86(1-2):63-68

34 Krishnamohan N, Lo C, Date RS. Predicting the degree of difficulty of laparoscopic cholecystectomy following endoscopic retrograde cholangiopancreatography - subgroup analysis does not improve the prediction. J Minim Access Surg 2019;15(4): 360-361

35 Cinar H, Ozbalci GS, Tarim IA, et al. Factors affecting the conversion to open surgery during laparoscopic cholecystectomy in patients with cholelithiasis undergoing ERCP due to choledocholithiasis. Ann Ital Chir 2017;88:229-236 